\section{Response to: 'Semi-quantitative analysis of line blot assay for myositis-specific and myositis- associated antibodies: a better performance?' by Cavazzana et al}

We have with great interest read the response from Cavazzana et al. ${ }^{1}$ We agree that increasing the cut-off of the line blot test for myositis-specific and myositis-associated autoantibodies could help to avoid false-positive responses. Our experience from more than a decade of using different versions of the Euroline (Euroimmun, Lübeck, Germany) line immunoassays (LIA) is, in agreement with the suggestion from Cavazzana et al that in the absolute majority of sera with multiple autoantibody specificities the autoantibody reactivities are present in the low range. When investigating only moderate and high reactivities from our previous comparison between LIA and an immunoprecipitation-based algorithm, ${ }^{2}$ we do, however, not generally improve the kappa statistics, in the way described by Cavazzana et al. We obtained an overall agreement between both approaches of $78 \%$ (vs previous 76\%) and a kappa coefficient 0.48 (vs previous 0.54). Regarding individual specificities, we did not find important differences neither in agreement nor in kappa statistics. Moreover, associations between relevant clinical features and positive autoantibodies remained similar.

Generally increasing the cut-offs to only regard samples with moderate (26-50 densitometry units (DU)) and high (>50 DU) reactivity as positive will also affect individual antibody specificities differently with the risk of missing clinically significant cases. We have, for example, observed patients presenting with amyopathic dermatomyositis and rapidly progressive interstitial lung disease with anti-MDA5 levels in the very low range. The trade-off between sensitivity and specificity is in this case very delicate.

There is a large variability how the Euroline LIA performs in different laboratories; the performance can vary with the temperature in the laboratory. ${ }^{3}$ The intensity of the band staining can also be evaluated either on wet or dried strips, and our impression is that this can induce considerable differences between reports from individual laboratories. A weakness with the assay is the lack of internal controls, monitoring the effect of differences in laboratory assay conditions. Bundell et al investigated 197 healthy controls with a previous version of the Euroline LIA (Euroline 3) according to the instructions from the manufacturer. They found 38 positive reactions for 10 myositis antibody specificities (excluding Ro52, not investigated by us), corresponding to a total diagnostic specificity of $98.9 \% .^{4}$ For the corresponding 10 specificities, we found one anti-Ku-positive serum among 60 healthy controls, corresponding to a diagnostic specificity of $99.8 \%$.

In agreement with others, we therefore think that calibration of the Euroline LIA is very important and that use of autoantibody-specific internal controls investigated in parallel to clinical samples on every test occasion should be mandatory in laboratories performing LIA for myositis autoantibodies. ${ }^{5}$ In our clinical laboratory at Uppsala University Hospital, we use a mix of six monospecific sera at different reactivity levels. During a 1 year follow-up, the coefficient of variation (CV \%) was inversely related to the mean antibody level for these six specificities $(\rho-0.95, p=0.0025)$. Consequently, the variation was strongest for reactivities in the low range close to the company-suggested cut-off where calibration is most important. We suggest that such internal control reagents used together with the Euroline LIA should primarily contain autoantibody reactivities in the low positive range.

In addition, we encourage international collaboration on further harmonisation/standardisation of analysis of myositisrelated autoantibodies. Evaluation of samples used in external quality assessment of laboratory results are probably not optimal in such evaluations as the bodies responsible for such programme have to choose samples where the results easily can be used do judge in individual laboratories (clearly positive or negative samples). ${ }^{6}$ The European Consensus Finding Study Group on autoantibodies, also known as the EULAR autoantibody study group, is one group that evaluates low level or otherwise challenging sera with the primary purpose to compare laboratory methodologies in a clinical context. ${ }^{6}$ We encourage more such international collaborative initiatives to enhance the possibility to compare myositis-specific and myositis-associated autoantibody profiles between different centres and to improve the diagnostic support of commercially available immunoassays that are becoming more widely available.

\section{Johan Rönnelid $\odot$, ${ }^{1}$ Fabricio Espinosa-Ortega $\odot, 2$ Ingrid E Lundberg $\oplus^{2,3}$ ${ }^{1}$ Department of Immunology, Genetics and Pathology, Uppsala University, Uppsala, Sweden \\ ${ }^{2}$ Division of Rheumatology, Department of Medicine, Karolinska Institutet, Stockholm, Sweden \\ ${ }^{3}$ Center for Molecular Medicine, Karolinska Institutet, Karolinska University Hospital, Stockholm, Sweden}

Correspondence to Professor Ingrid E Lundberg, Rheumatology, Karolinska University Hospital, Stockholm, SE 171 76, Sweden; ingrid.lundberg@ki.se

Collaborators Marie Holmqvist, Helene Alexanderson, Helena Storfors, Tsuneyo Mimori.

Contributors All authors have contributed to writing of this correspondence and agree to the content of this correspondence. All authors have also contributed to the data collection and analyses that are mentioned in the letter.

Funding The authors have not declared a specific grant for this research from any funding agency in the public, commercial or not-for-profit sectors.

Competing interests No, there are no competing interests for any author.

Patient consent for publication Not required.

Provenance and peer review Commissioned; internally peer reviewed.

(c) Author(s) (or their employer(s)) 2020. No commercial re-use. See rights and permissions. Published by BMJ.

\section{Check for updates}

To cite Rönnelid J, Espinosa-Ortega F, Lundberg IE. Ann Rheum Dis 2020;79:e153.

Received 30 June 2019

Accepted 4 July 2019

Published Online First 15 July 2019

\section{S Linked}

- http://dx.doi.org/10.1136/annrheumdis-2019-215884

Ann Rheum Dis 2020;79:e153. doi:10.1136/annrheumdis-2019-215967

ORCID iDs

Johan Rönnelid http://orcid.org/0000-0003-1186-3226

Fabricio Espinosa-Ortega http://orcid.org/0000-0001-6227-8209

Ingrid E Lundberg http://orcid.org/0000-0002-6068-9212

\section{REFERENCES}

1 Cavazzana I, Fredi M, Franceschini F. Semi-Quantitative analysis of line blot assay for myositis-specific and myositis-associated antibodies: a better performance? Ann Rheum Dis 2020;79:e152. 
2 Espinosa-Ortega F, Holmqvist M, Alexanderson H, et al. Comparison of autoantibody specificities tested by a line blot assay and immunoprecipitation-based algorithm in patients with idiopathic inflammatory myopathies. Ann Rheum Dis 2019:78:858-60.

3 Rönnelid J, Barbasso Helmers S, Storfors H, et al. Use of a commercial line blot assay as a screening test for autoantibodies in inflammatory myopathies. Autoimmun Rev 2009;9:58-61.
4 Bundell C, Rojana-Udomsart A, Mastaglia F, et al. Diagnostic performance of a commercial immunoblot assay for myositis antibody testing. Pathology 2016;48:363-6.

5 Mahler M, Fritzler MJ. Detection of myositis-specific antibodies: additional notes. Ann Rheum Dis 2019;78:e45.

6 Rönnelid J. The choice of laboratory methodology influences autoantibody test results. Front Immunol 2015;6:392. 